\title{
Parallel Regulation of a Modulator-Activated Current via Distinct Dynamics Underlies Comodulation of Motor Circuit Output
}

\author{
Nicholas D. DeLong, ${ }^{\star}$ Matthew S. Kirby, ${ }^{\star}$ Dawn M. Blitz, and Michael P. Nusbaum \\ Department of Neuroscience, University of Pennsylvania School of Medicine, Philadelphia, Pennsylvania 19104-6074
}

\begin{abstract}
The cellular mechanisms underlying comodulation of neuronal networks are not elucidated in most systems. We are addressing this issue by determining the mechanism by which a peptide hormone, crustacean cardioactive peptide (CCAP), modulates the biphasic (protraction/retraction) gastric mill (chewing) rhythm driven by the projection neuron MCN1 in the crab stomatogastric ganglion. MCN1 activates this rhythm by slow peptidergic (CabTRP Ia) and fast GABAergic excitation of the reciprocally inhibitory central pattern generator neurons LG (protraction) and Int1 (retraction), respectively. MCN1 synaptic transmission is limited to the retraction phase, because LG inhibits MCN1 during protraction. Bath-applied CCAP also excites both LG and Int1, but selectively prolongs protraction. Here, we use computational modeling and dynamic-clamp manipulations to establish that CCAP prolongs the gastric mill protractor (LG) phase and maintains the retractor (Int1) phase duration by activating the same modulator-activated inward current $\left(I_{\mathrm{MI}}\right)$ in LG as MCN1-released CabTRP Ia. However, the CCAP-activated current $\left(I_{\mathrm{MI}-\mathrm{CCAP}}\right)$ and MCN1-activated current $\left(I_{\mathrm{MI}-\mathrm{MCN} 1}\right)$ exhibit distinct time courses in LG during protraction. This distinction results from $I_{\mathrm{MI}-\mathrm{CCAP}}$ being regulated only by postsynaptic voltage, whereas $I_{\mathrm{MI}-\mathrm{MCN} 1}$ is also regulated by LG presynaptic inhibition of MCN1. Hence, without CCAP, retraction and protraction duration are determined by the time course of $I_{\mathrm{MI}-\mathrm{MCN} 1}$ buildup and feedback inhibition-mediated decay, respectively, in LG. With $I_{\mathrm{MI}-\mathrm{CCAP}}$ continually present, the impact of the feedback inhibition is reduced, prolonging protraction and maintaining retraction duration. Thus, comodulation of rhythmic motor activity can result from convergent activation, via distinct dynamics, of a single voltage-dependent current.
\end{abstract}

\section{Introduction}

The parallel influence of distinct modulatory inputs is likely a common occurrence in the CNS, yet its impact on neuronal network output is described in only a few systems (Dickinson et al., 1997; Svensson et al., 2001; McLean and Sillar, 2004; Crisp and Mesce, 2006; Kirby and Nusbaum, 2007). Such parallel inputs might target the same, overlapping or distinct sets of network neurons, and they could act via convergent or distinct mechanisms. This level of mechanistic detail regarding comodulation, however, is unavailable for most networks, though it is partly established for the motor network output onto motor neurons in some spinal locomotor systems (Svensson et al., 2001; McLean and Sillar, 2004).

We are studying the mechanisms underlying comodulation of motor pattern generation using the stomatogastric nervous system (STNS) of the crab Cancer borealis (Nusbaum and Beenhakker, 2002; Marder and Bucher, 2007). Within the STNS, the stomato-

\footnotetext{
Received June 29, 2009; revised Aug. 4, 2009; accepted Aug. 24, 2009.

This work was supported by National Institute of Neurological Disorders and Strokes Grants R37-NS29436 (M.P.N.) and F31-NS58013 (N.D.D.). We thank Aaron Cook for assistance with dissections for the voltage-clamp experiments.

*N.D.D. and M.S.K. contributed equally to this work.

Correspondence should be addressed to Dr. Michael P. Nusbaum, Department of Neuroscience, 215 Stemmler Hall, University of Pennsylvania School of Medicine, Philadelphia, PA 19104-6074. E-mail: nusbaum@mail. med.upenn.edu.

D0I:10.1523/JNEUROSCI.3079-09.2009

Copyright $\odot 2009$ Society for Neuroscience $\quad 0270-6474 / 09 / 2912355-13 \$ 15.00 / 0$
}

gastric ganglion (STG) contains the central pattern generator (CPG) circuits for the gastric mill (chewing) and pyloric (filtering of chewed food) rhythms. Modulatory projection neurons that regulate these $\mathrm{CPGs}$ are located primarily in the commissural ganglia (CoGs) (Coleman et al., 1992; Nusbaum et al., 2001).

The peptide hormone crustacean cardioactive peptide (CCAP) modulates the biphasic gastric mill rhythm driven by the projection neuron modulatory commissural neuron 1 (MCN1), by selectively prolonging the gastric mill protractor phase (Kirby and Nusbaum, 2007). MCN1 activates the gastric mill CPG via slow, peptidergic (CabTRP Ia) excitation of the protractor CPG neuron lateral gastric (LG) and fast, ionotropic (GABA) excitation of the retractor CPG neuron interneuron 1 (Int1) (Wood et al., 2000; Stein et al., 2007). MCN1 cotransmitter release occurs primarily during retraction, due to feedback inhibition from LG during protraction (Coleman et al., 1995). CCAP also excites LG and Int1 (Kirby and Nusbaum, 2007). Additionally, CCAP and CabTRP Ia activate the same modulator-activated, voltagedependent inward current $\left(I_{\mathrm{MI}}\right)$ in pyloric neurons (Swensen and Marder, 2000, 2001), suggesting a comparable convergence in gastric mill neurons.

Here we test and confirm the hypothesis that CCAP comodulates the MCN1-gastric mill rhythm by convergent activation of an ionic current $\left(I_{\mathrm{MI}}\right)$ in the LG neuron. Also pivotal is that, unlike MCN1-activated $I_{\mathrm{MI}}\left(I_{\mathrm{MI}-\mathrm{MCN} 1}\right)$, the CCAP-activated $I_{\mathrm{MI}}$ $\left(I_{\mathrm{MI}-\mathrm{CCAP}}\right)$ is independent of LG synaptic control. The latter distinction results in the two $I_{\mathrm{MI}}$ components exhibiting dif- 
ferent dynamics during protraction, including a sustained $I_{\mathrm{MI}-\mathrm{CCAP}}$ amplitude and a declining $I_{\mathrm{MI}-\mathrm{MCN} 1}$ amplitude. By manipulating $I_{\mathrm{MI}-\mathrm{CCAP}}$ in LG during the MCN1-gastric mill rhythm, we show that $I_{\mathrm{MI}-\mathrm{CCAP}}$ is necessary and sufficient for enabling CCAP to prolong protraction and maintain retraction duration. Specifically, protraction is prolonged by $I_{\mathrm{MI}-\mathrm{CCAP}}$ summing with $I_{\mathrm{MI}-\mathrm{MCN} 1}$ to maintain LG suprathreshold for a longer duration. With protraction prolonged, however, $I_{\mathrm{MI}-\mathrm{MCN} 1}$ decays further. Without compensation, this result would prolong retraction, because it would take longer for $I_{\mathrm{MI}-\mathrm{MCN} 1}$ to build up sufficiently for LG to burst. However, $I_{\mathrm{MI}-\mathrm{CCAP}}$ sums with $I_{\mathrm{MI}-\mathrm{MCN} 1}$ during retraction to prevent a change in retraction duration. Thus, comodulation of CPG activity can result from convergent ionic current activation, acting in part via distinct time courses.

\section{Materials and Methods}

Animals. Male Jonah crabs (Cancer borealis) were obtained from commercial suppliers (Yankee Lobster; Marine Biological Laboratory). Crabs were housed in commercial tanks containing recirculating, aerated, artificial seawater $\left(10-12^{\circ} \mathrm{C}\right)$. Before dissection, the crabs were cold anesthetized by packing them in ice for at least $30 \mathrm{~min}$. The foregut was then removed and maintained in chilled physiological saline while the STNS was dissected from it and pinned down in a saline-filled silicone elastomer-lined Petri dish (Sylgard 184, KR Anderson).

Solutions. The isolated STNS was maintained in C. borealis saline containing the following (in mM): $439 \mathrm{NaCl}, 26 \mathrm{MgCl}_{2}, 13 \mathrm{CaCl}_{2}$, $11 \mathrm{KCl}, 10$ Trizma base, and 5 maleic acid, $\mathrm{pH}$ 7.4-7.6. During experimentation, the preparation was continuously superfused with this solution $\left(7-12 \mathrm{ml} / \mathrm{min}, 10-12^{\circ} \mathrm{C}\right)$. For voltageclamp experiments, TTX $\left(10^{-7} \mathrm{M}\right.$, Sigma $)$, picrotoxin $\left(10^{-5} \mathrm{M}\right.$, Sigma), TEACl $\left(10^{-2} \mathrm{M}\right.$, Sigma), and $\mathrm{CdCl}_{2}\left(2 \times 10^{-4} \mathrm{M}\right.$, Fluka Chemical) were added to $C$. borealis saline. These pharmacological agents were used to suppress sodium currents (TTX), glutamatergic inhibitory synaptic transmission (picrotoxin), a subset of potassium currents (TEACl) and a subset of calcium currents $\left(\mathrm{CdCl}_{2}\right)$ (Marder and Eisen, 1984; Golowasch and Marder, 1992a). CCAP (Bachem Americas) and CabTRP Ia (Biotechnology Center, University of Wisconsin, Madison, WI) were diluted from stock solutions into normal C. borealis saline or the voltage-clamp saline immediately before use.

Electrophysiology. All experiments were conducted using the isolated STNS, from which the CoGs were removed by transecting the superior (sons) and inferior (ions) oesophageal nerves (Fig. 1A). Intracellular and extracellular recordings of gastric mill neurons were made using routine methods for the STNS (Beenhakker and Nusbaum, 2004). Sharp glass microelectrodes (current clamp: 15-30 M 2 ; voltage clamp: 15-20 M $\Omega$ ), filled with $4 \mathrm{~m} \mathrm{~K}$-acetate plus $20 \mathrm{~mm} \mathrm{KCl}$ or $0.6 \mathrm{M} \mathrm{K}_{2} \mathrm{SO}_{4}$ plus $10 \mathrm{~mm} \mathrm{KCl}$, were used for intracellular recordings. Intracellular recordings were made with Axoclamp 2 and 900A amplifiers (Molecular Devices), and intracellular current-clamp injections were performed in single electrode discontinuous current-clamp (DCC) mode with sample rates of

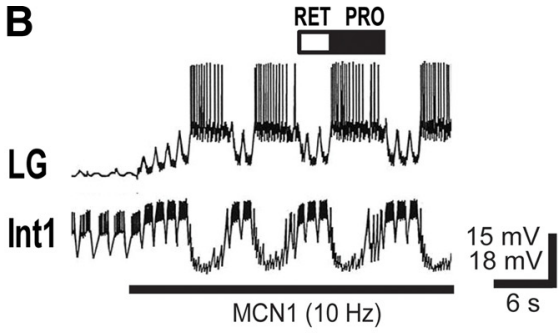

C
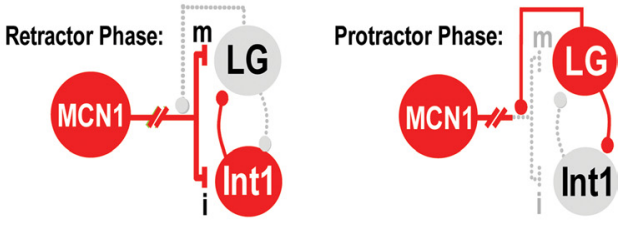

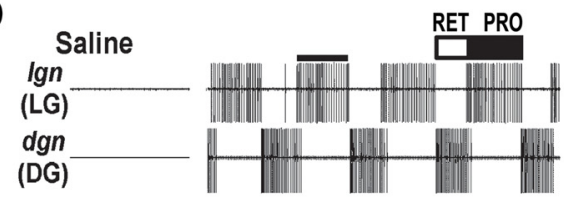

$\operatorname{CCAP}\left(10^{-7} \mathrm{M}\right)$

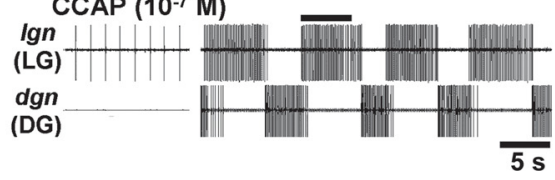

Figure 1. Schematics of the isolated stomatogastric nervous system and the core CPG circuit for the MCN1-elicited gastric mill rhythm, plus examples of the MCN1-elicited gastric mill rhythm and the influence of the peptide hormone CCAP on this rhythm. A, The STNS consists of the unpaired STG and OG plus the paired CoGs. There is a single MCN1 in each CoG. The paired lines crossing

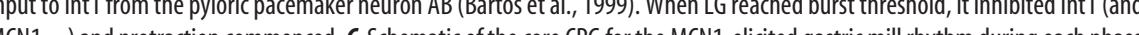
of this rhythm. Despite the schematic representation of synapses onto somata, all synapses are located on small neuronal branches in the STG neuropil. Active neurons have red-filled somata, while inactive neurons have gray-filled somata. Small filled circles represent synaptic inhibition, while t-bars represent synaptic excitation; $\mathrm{m}$, metabotropic; $\mathrm{i}$, ionotropic. $\mathrm{C}$ is based on Coleman et a. (1995) and Bartos et al. (1999). D, As shown by Kirby and Nusbaum (2007), bath-applied CCAP selectively prolongs the simulation. Retraction is represented by the dorsal gastric (DG) retractor motor neuron. The bar on top of the second LG burst in each panel represents the $L G$ burst duration in saline, to show that the $L G$ burst is prolonged by CCAP.

2-5 kHz. Discontinuous single electrode voltage-clamp (dSEVC) recordings were performed with sampling rates of $5-15 \mathrm{kHz}$. To facilitate intracellular recordings, the STG was desheathed and visualized with light transmitted through a dark-field condenser (Nikon).

For dSEVC recordings made from the LG primary neurite within the STG neuropil, LG was first filled with Alexa 568 (Invitrogen) using an intrasomatic recording. The LG neuropil arborization was then visualized with a TXR filter set on a MZ16F epifluorescence microscope (Leica) to enable impalement of the primary LG neurite with a second microelectrode, which was then used to perform dSEVC recordings of total cell currents. The somatic impalement was maintained to verify that the correct neurite was being recorded once action potentials were eliminated with TTX. Voltage ramps ( -90 to $0 \mathrm{mV}$ at a rate of $75 \mathrm{mV} / \mathrm{s}$ ) and steps ( -90 to $0 \mathrm{mV}$ in 5 or $10 \mathrm{mV}$ increments, $500 \mathrm{~ms}$ duration) were applied and currents were recorded using PClamp (version 9.2; Molecular Devices) and Digidata 1322A (Molecular Devices). In some experiments, as noted, CabTRP Ia was applied via pressure ejection (10 psi, $5 \mathrm{~s}$ duration) from a microelectrode positioned slightly above the STG neuropil using a Picospritzer II (Parker Hannifin). 
Table 1. Gastric mill rhythm model parameters for $I_{\text {MI-MCN1 }}$ and $I_{\text {MI-CCAP }}$

\begin{tabular}{|c|c|c|c|c|c|c|c|}
\hline Current & $G_{\max }$ & $E_{\text {rev }}$ & $m_{\mathrm{inf}}$ & $m_{\mathrm{tau}}$ & $m_{\text {postinf }}$ & $m_{\text {posttau }}$ & $m_{\text {power }}$ \\
\hline \multirow[t]{2}{*}{$I_{\text {MI-MCN1 }}$} & \multirow[t]{2}{*}{10} & \multirow[t]{2}{*}{0} & 1 & 9000 & 1 & 50 & $\mathrm{n} / \mathrm{a}$ \\
\hline & & & $\overline{1+e^{-2\left(V_{\mathrm{MCN} 1}+68\right)}}$ & $8000+\overline{1+e^{-2\left(V_{\mathrm{MCN} 1}+68\right)}}$ & $\overline{1+e^{-0.1\left(V_{\mathrm{LG}}+50\right)}}$ & & \\
\hline \multirow{2}{*}{$I_{\mathrm{MI-CCAP}}$} & \multirow[t]{2}{*}{0.2} & \multirow[t]{2}{*}{0} & 1 & \multirow[t]{2}{*}{50} & \multirow[t]{2}{*}{$\mathrm{n} / \mathrm{a}$} & \multirow[t]{2}{*}{$\mathrm{n} / \mathrm{a}$} & \multirow[t]{2}{*}{1} \\
\hline & & & $1+e^{-0.1\left(V_{\mathrm{LG}}+50\right)}$ & & & & \\
\hline
\end{tabular}

The values used for $I_{\text {MI-MCN1 }}$ and $I_{\text {MI-CCAP }}$ in the computational model of the MCN1-elicited gastric mill rhythm. The other model parameters were unchanged from previous studies (Nadim et al., 1998; Beenhakker et al., 2005). $G_{\text {max }}$ Conductance value at maximum activation; $E_{\text {rev }}$, reversal potential; $m_{\text {inf }}$, steady-state activation curve; $m_{\text {tau }}$, activation time constant; $m_{\text {postinf }}$, steady-state activation curve for the postsynaptic voltage dependence; $m_{\text {posttau }}$, activation time constant for the postsynaptic voltage dependence; $m_{\text {power }}$, integer power of the activation variable $m ; n / a$, not relevant to computation. Parameter names are derived from the nomenclature used in the Network modeling software, which was used to perform all simulations (http://stg.rutgers.edu/software/network.htm).

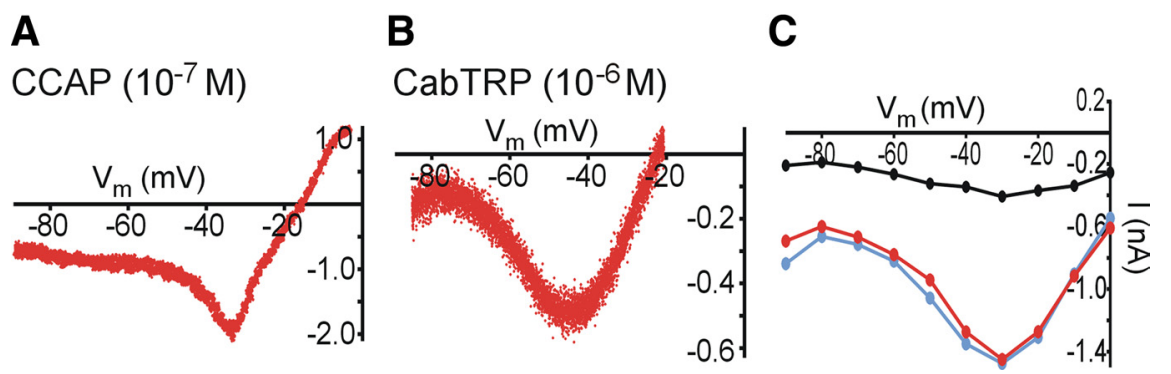

Figure 2. The peptides CCAP and CabTRP la activate the same voltage-dependent inward current in the LG neuron. $\boldsymbol{A}, \boldsymbol{B}$, Subtracting the total average current elicited by voltage ramps ( -90 to $0 \mathrm{mV}, 75 \mathrm{mV} / \mathrm{s}$ ) in control conditions from the total current elicited in $10^{-7} \mathrm{M} C \mathrm{CAP}(\boldsymbol{A})$ or $10^{-6} \mathrm{M}$ CabTRP la $(\boldsymbol{B})$ revealed a voltage-dependent inward current. The currents plotted are the difference currents resulting from subtracting the average of $20(\boldsymbol{A})$ or $30(\boldsymbol{B})$ ramp trials in each condition. $\boldsymbol{C}$, Voltage steps ( -90 to $0 \mathrm{mV}, 10 \mathrm{mV}$ increments, $500 \mathrm{~ms}$ duration) were used to measure the currents activated by pressure applied CabTRP la $\left(10^{-4} \mathrm{M} ; 10 \mathrm{psi}, 5 \mathrm{~s}\right.$; black line and symbols), CCAP ( $10^{-6} \mathrm{M}$; bath application; red line and symbols) and CabTRP la in the presence of CCAP (blue line and symbols). In each case, the control current was subtracted from the experimental condition and the difference currents are plotted. In this example, the $I_{\text {Peak }}$ for CabTRP la alone was $\sim-0.4 \mathrm{nA}$, but with CCAP present the $I_{\text {Peak }}$ added by CabTRP la was $\sim-0.02 \mathrm{nA}$. Each plot is the mean steady-state current (last $200 \mathrm{~ms}$ of a step) at each voltage, from the average of 5 sets of steps. The different $E_{\text {rev }}$ in $\boldsymbol{A} / \boldsymbol{B}$ and $\boldsymbol{C}$ reflects the variability in measured $E_{\mathrm{rev}}$ for $I_{\mathrm{MI}}$ in this and previous work (Golowasch and Marder, 1992a). This variability is likely due to the relatively large leak- and voltage-dependent outward currents in STG neurons at depolarized voltages (Golowasch and Marder, 1992b; Khorkova and Golowasch, 2007). However, within each experiment, $E_{\text {rev }}$ for $I_{\text {MI-CabTRP Ia }}$ and $I_{\text {MI-cCAP }}$ was similar, and in all experiments, the measured $E_{\text {rev }}$ was comparable to those previously reported (Golowasch and Marder, 1992a). A-C were different preparations.

Each extracellular nerve recording was made using a pair of stainlesssteel wire electrodes (reference and recording), the ends of which were pressed into the Sylgard-coated dish. A differential AC amplifier (Model 1700: AM Systems) amplified the voltage difference between the reference wire, placed in the bath, and the recording wire, placed near an individual nerve and isolated from the bath by petroleum jelly (Vaseline, Lab Safety Supply). This signal was then further amplified and filtered (Model 410 Amplifier: Brownlee Precision). Extracellular nerve stimulation was accomplished by placing the pair of wires used to record nerve activity into a stimulus isolation unit (SIU 5: Astromed/Grass Instruments) that was connected to a stimulator (Model S88: Astromed/Grass Instruments).

To elicit the gastric mill rhythm in the isolated STG, we selectively activated MCN1 by tonic extracellular stimulation of one or both of the transected ions, on the STG side of the transection (Fig. 1) (Bartos and Nusbaum, 1997; Bartos et al., 1999). Individual STNS neurons were identified by their axonal pathways, activity patterns and interactions with other neurons (Weimann et al., 1991; Blitz et al., 1999; Beenhakker and Nusbaum, 2004). During the MCN1-gastric mill rhythm, the LG burst defines the protractor phase while its interburst duration, which is equivalent to the duration of Int 1 activity, defines the retractor phase (Coleman et al., 1995; Bartos et al., 1999; Kirby and Nusbaum, 2007).

Dynamic clamp. We used the dynamic clamp to inject an artificial version of an ionic current $\left(I_{\mathrm{MI}}\right)$ into the LG neuron (Sharp et al., 1993; Bartos et al., 1999; Prinz et al., 2004; Beenhakker et al., 2005; Goaillard and Marder, 2006). The dynamic-clamp software uses the intracellularly recorded membrane potential of a biological neuron to calculate an artificial current $\left(I_{\mathrm{dyn}}\right)$ using a conductance $\left[g_{\mathrm{dyn}}(t)\right]$ that is numerically computed, as well as a predetermined reversal potential $\left(E_{\mathrm{rev}}\right)$. The injected current is based upon real time computations, updated in each time step $(0.2 \mathrm{~ms})$ according to the new values of recorded membrane potential, and injected back into the biological neuron. The intrinsic currents are computed according to the following equations:

$$
\begin{gathered}
I_{\mathrm{dyn}}=g_{\mathrm{dyn}} m^{p} h^{q}\left(V_{1}-E_{\mathrm{rev}}\right) \\
\tau_{X}\left(V_{2}\right) \frac{d X}{d t}=X_{\infty}\left(V_{2}\right)-X ; X=m, h \\
X_{\infty}(V)=\frac{1}{1+\exp \left(\frac{V-V_{X}}{k_{X}}\right)} \\
\tau_{X}(V)=\tau_{X, \mathrm{Lo}}+\frac{\tau_{X, \mathrm{Hi}}-\tau_{X, \mathrm{Lo}}}{1+\exp \left(-\frac{V-V_{X}}{\left|k_{X}\right|}\right)}
\end{gathered}
$$

where $V_{1}$ and $V_{2}$ both represent the membrane potential, and $X$ stands for either $m$ or $h$ for calculations involving activation or inactivation, respectively.

In our dynamic-clamp experiments, we modeled $I_{\mathrm{MI}}$ using parameters both previously determined (Golowasch and Marder, 1992a; Swensen and Marder, 2000, 2001) and determined during the voltage-clamp experiments in the LG neuron (see Results). Specifically, we set the half-maximum voltage of the activation curve $\left(V_{\mathrm{m}}\right)$ at $-45 \mathrm{mV}$, with the peak current occurring at $-37 \mathrm{mV}$. We set the reversal potential $\left(E_{\text {rev }}\right)$ to $0 \mathrm{mV}$, consistent with our findings and previous voltage-clamp results for $I_{\mathrm{MI}}$ (Golowasch and Marder, 1992a). $I_{\mathrm{MI}}$ shows a voltage dependence to its activation (Golowasch and Marder, 1992a; Swensen and Marder, 2000, 2001). Therefore, the integer power of the activation variable $m$ (abbreviated " $p$ " above) was set to a value of 1 . The slope of the activation sigmoid at half-maximum $\left(K_{\mathrm{m}}\right)$ was $-5.0 \mathrm{mV}$, the time constant of activation at membrane potentials below $V_{\mathrm{m}}\left(\tau_{\mathrm{m}, \mathrm{Lo}}\right)$ was $50.0 \mathrm{~ms}$ and the activation time constant at membrane voltages above $V_{\mathrm{m}}\left(\tau_{\mathrm{m}, \mathrm{Hi}}\right)$ was $100.0 \mathrm{~ms}$. $I_{\mathrm{MI}}$ does not inactivate, so the integer power of the inactivation variable $h$ (abbreviated " $q$ " above) was set to 0 . Therefore, no values were needed for $K_{\mathrm{h}}, \tau_{\mathrm{h}, \mathrm{Lo}}$, and $\tau_{\mathrm{h}, \mathrm{Hi}}$, all of which are used to calculate the inactivation of the current. The conductance value at maximum activation $\left(G_{\max }\right)$ varied between 5 and $30 \mathrm{nS}$, depending on the experiment. In all of our dynamic-clamp experiments, the maximum current injected into the LG neuron never exceeded $1 \mathrm{nA}$ (see Results).

We used a version of the dynamic clamp developed in the Nadim laboratory (Rutgers University, Newark, NJ; available at http://stg.rutgers. edu/software/) to run on a personal computer (PC) running Windows $\mathrm{XP}$ and a NI PCI-6070-E data acquisition board (National Instruments). As above, all dynamic-clamp current injections were performed while recording in single-electrode, DCC mode (sample rates $2-5 \mathrm{kHz}$ ).

Data analysis. Data analysis was facilitated by a custom-written program (The Crab Analyzer) for Spike2 (Cambridge Electronic Design) that determines the activity levels and burst relationships of individual neurons (freely available at http://www.uni-ulm.de/ wstein/spike2/index. html). Unless otherwise stated, each datum in a dataset was derived by determining the average of 10 consecutive gastric mill-timed impulse bursts in the biological preparation, or the average of three consecutive 
cycles for the computational modeling studies. In all experiments, the burst duration was defined as the duration (in seconds) between the onset of the first and last action potential in an impulse burst. The average firing rate was determined by the number of action potentials minus one divided by the burst duration. Protractor phase duration was equivalent to LG burst duration, and retractor phase duration was equivalent to the LG interburst duration (time between the last action potential in one LG burst and the first action potential in the next LG burst). The cycle period of the gastric mill rhythm was determined by calculating the duration between the onset of successive LG neuron bursts.

Voltage-clamp data analysis was performed using PClamp software. Total cell currents were determined either by averaging 2-3 sets of 10 ramps or 5-10 sets of steps in each condition and subtracting the control from the experimental condition. The voltage-dependent inward current originally described by Golowasch and Marder (1992a) was identified as a proctolinactivated current and thus designated $I_{\text {proct }}$. However, it is now known that many modulators activate this current (Swensen and Marder, 2000, 2001). Consequently, this current is now designated as the modulator-activated inward current $\left(I_{\mathrm{MI}}\right)$ (Grashow et al., 2009).

Data were collected onto a chart recorder (Models MT 95000 and Everest: Astromed) and simultaneously onto a PC computer using data acquisition/analysis tools (Spike2; digitized at $\sim 5$ $\mathrm{kHz}$ ). Figures were made from Spike2 or PClamp files incorporated into Adobe Illustrator (Adobe) or Igor Pro (Wavemetrics) and CorelDraw (Corel). Statistical analyses were performed with SigmaStat 3.0 and SigmaPlot 8.0 (SPSS). All comparisons were made using the paired Student's $t$ test, except where noted. Data are expressed as the mean \pm SE.

Gastric mill model. We constructed a computational model modified from an existing conductance-based model of the gastric mill circuit (Nadim et al., 1998; Beenhakker et al., 2005). The previously published version mod-

eled the LG, Int1, and MCN1 neurons as having multiple compartments separated by an axial resistance, with each compartment possessing intrinsic and/or synaptic conductances. To more realistically mimic the biological system, in this version of the model we modified the MCN1activated synaptic conductance $\left(G_{\mathrm{MI}-\mathrm{MCN} 1}\right)$ in the dendrite compartment of the LG neuron to include a postsynaptic voltage dependence (Table 1). The parameters of this model current were based on both a previously published voltage-clamp analysis of this current in the pyloric LP neuron and on the LG neuron voltage-clamp results obtained in this paper (Golowasch and Marder, 1992a; Swensen and Marder, 2000, 2001) (see Results). To mimic the effects of CCAP bath application to the biological system, we also added to the LG neuron dendrite compartment an intrinsic (nonsynaptically activated) current $\left(I_{\text {MI-CCAP }}\right.$ ) with the same voltage dependence as $I_{\mathrm{MI}-\mathrm{MCN} 1}$ (Table 1 ). This approach was based on the fact that CCAP and MCN1-released CabTRP Ia both excite LG (Wood et al., 2000; Kirby and Nusbaum, 2007; Stein et al., 2007), and activate $I_{\mathrm{MI}}$ in STG pyloric neurons (Swensen and Marder, 2000, 2001), as well as LG (this paper).

Simulations were performed on a PC with Windows XP. We used the Network simulation software developed in the Nadim laboratory (http://stg.rutgers.edu/software/network.htm), which was run using the freely available CYGWIN Linux emulation software package. We used a fourth-order Runge-Kutta numerical integration method with time steps of 0.05 and $0.01 \mathrm{~ms}$. Results were visualized by plotting outputted data points using the freely available Gnuplot software package (www. gnuplot.info). In most figures showing the model output, we present $G_{\mathrm{MI}-\mathrm{MCN} 1}$ and/or $G_{\mathrm{MI}-\mathrm{CCAP}}$ instead of their associated $I_{\mathrm{MI}}$ to more clearly display their trajectory during the gastric mill retractor and protractor phases. $G_{\mathrm{MI}}$ parallels $I_{\mathrm{MI}}$ except for the fast $I_{\mathrm{MI}}$ transient that occurs during each LG action potential (see Fig. 3). The fast transients result from the voltage sensitivity of $I_{\mathrm{MI}}$, which is not shared by $G_{\mathrm{MI}}$. It is also noteworthy that the presentation of $I_{\mathrm{MI}}$ in the model and dynamic-clamp figures represents different conventions. Specifically, the model output directly reports actual current flow in the model neuron and so uses the standard voltage-clamp convention, whereas the dynamic-clamp output represents the current injected into the neuron and hence uses the standard current-clamp convention. Consequently, $I_{\mathrm{MI}}$ is represented as an inward (downward trajectory) current in the model output figures but is represented as a depolarizing (upward trajectory) current in the dynamic-clamp output figures.

\section{Results}

The gastric mill system in C. borealis

The gastric mill rhythm (cycle period 5-20 s) controls the rhythmic protraction and retraction chewing movements of the teeth in the gastric mill stomach compartment (Heinzel et al., 1993). 

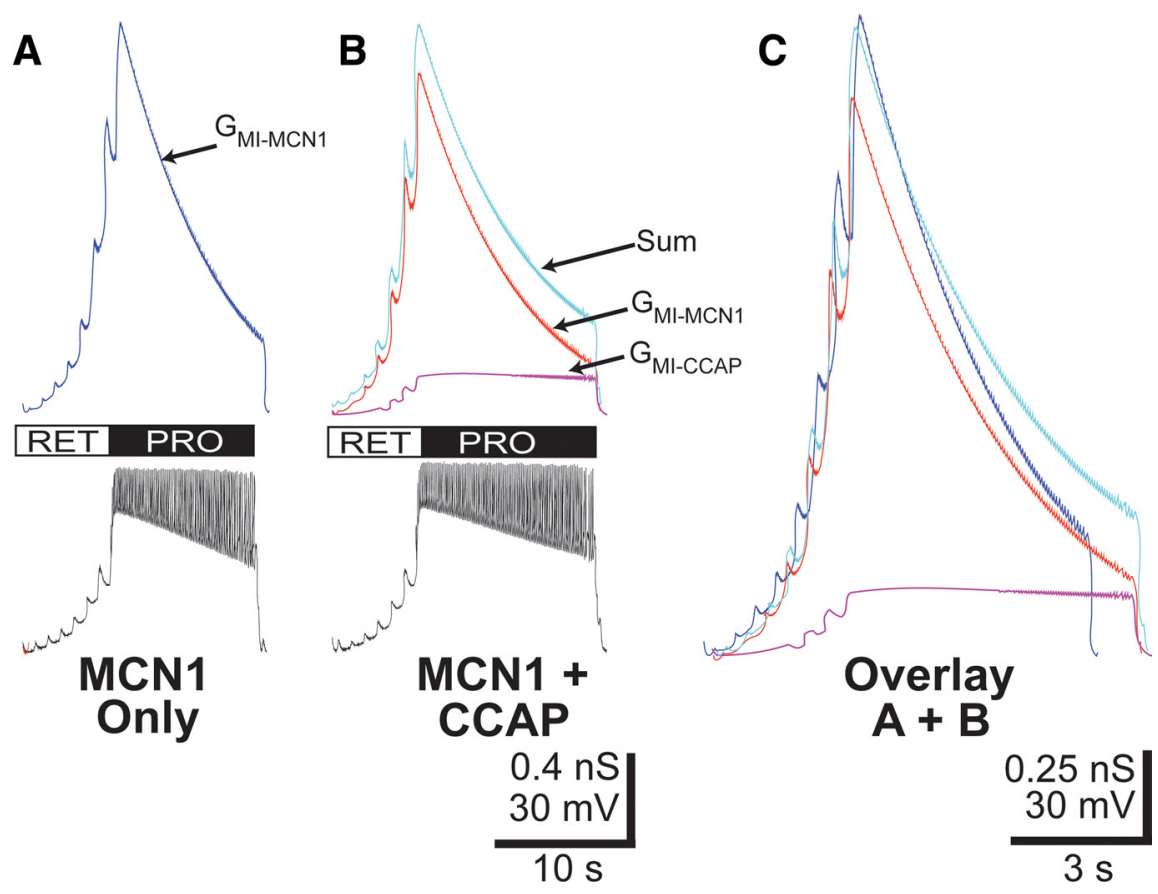

Figure 4. MCN1- and CCAP-activated $G_{M I}$ in $L G$ exhibit different dynamics during the MCN1-gastric mill rhythm, but the total peak $G_{M l}$ activated during this rhythm is the same when MCN1 is stimulated in saline and with CCAP present. Using the computational model, the $G_{M l}$ trajectory and amplitude during a single cycle of the gastric mill rhythm are shown when MCN1 is stimulated without CCAP $(\boldsymbol{A})$ and with CCAP present $(\boldsymbol{B})$. "Sum" represents the summation of $G_{\text {MI-MCN1 }}$ and $G_{\text {MI-CCAP. }}$, Overlay of $\boldsymbol{A}$ and $\boldsymbol{B}$ indicate that the summed peak $G_{\mathrm{MI}}$ in $\boldsymbol{B}$ is the same as $G_{\mathrm{MI}-\mathrm{MCN} 1}$ from $\boldsymbol{A}$.

This rhythm is thus composed of alternating impulse bursts in protractor and retractor motor neurons, plus a single retractor phase interneuron (Int1) (Fig. 1 B) (Kirby and Nusbaum, 2007). Several gastric mill neurons coincidentally exhibit faster rhythmic impulse bursts that are time locked to the pyloric rhythm (cycle period 0.5-2 s) (Weimann et al., 1991; Kirby and Nusbaum, 2007). The pyloric rhythm controls the filtering of chewed food in the pylorus, which is the stomach compartment immediately posterior to the gastric mill. Int1 is one of the neurons exhibiting this dual rhythmic firing pattern during the MCN1elicited gastric mill rhythm (Fig. 1B) (Bartos et al., 1999). Both LG and Int 1 are present as single neurons in the C. borealis STG.

The core CPG underlying the MCN1-gastric mill rhythm includes the reciprocally inhibitory protractor phase neuron LG and retractor phase neuron Int1, plus the STG terminals of MCN1 ( MCN1 $_{\mathrm{STG}}$ ) (Fig. 1C) (Coleman et al., 1995; Bartos et al., 1999). The gastric mill cycle period is also regulated by the pyloric pacemaker neurons, via an inhibitory synapse from the anterior burster (AB) neuron onto Int1 (Bartos et al., 1999). During retraction, the slow MCN1 excitation of LG builds up until LG escapes from Int1-mediated inhibition and initiates an action potential burst that starts the protractor phase. During protraction, the LG burst inhibits Int 1 and also inhibits $\mathrm{MCN1}_{\mathrm{STG}}$ transmitter release, thereby reducing or removing further MCN1 excitation of LG (Fig. 1C). Hence, the LG burst persists only until the slowly decaying effects of the peptidergic excitation from MCN1 no longer maintain LG at a sufficiently depolarized membrane potential, at which point the protractor phase terminates and retraction resumes.

Superfusing CCAP $\left(\geq 10^{-10} \mathrm{M}\right)$ to the isolated STG slows the MCN1-gastric mill rhythm by selectively prolonging the protractor phase (Fig. 1D) (Kirby and Nusbaum, 2007). This response occurs despite the fact that CCAP directly excites both LG and Int 1, while having no effect on $\mathrm{MCN1}_{\mathrm{STG}}$ (Kirby and Nusbaum, 2007). Hence, during the CCAPmodulated gastric mill rhythm, LG exhibits prolonged bursts with an increased firing frequency, but Int 1 activity is unchanged (Kirby and Nusbaum, 2007). Additionally, despite its lack of effect on $\mathrm{MCN1}_{\mathrm{STG}}$, CCAP lowers the threshold MCN1 firing frequency necessary to elicit the gastric mill rhythm (Kirby and Nusbaum, 2007). Here, our goal was to determine the mechanism(s) by which CCAP selectively prolongs the protractor phase of the MCN1-gastric mill rhythm and facilitates the ability of MCN1 to activate this rhythm.

\section{CCAP and CabTRP Ia both activate $I_{M I}$ in the LG neuron}

To determine the mechanism whereby CCAP modulates the MCN1-gastric mill rhythm, we first identified the ionic currents in LG that were influenced by MCN1 and CCAP using dSEVC recordings from the LG primary neurite (see Materials and Methods). To obtain voltage clamp of sufficient quality, we conducted these experiments with action potentials suppressed, which prevented us from identifying the MCN1-activated current(s) via MCN1 stimulation. However, because CabTRP Ia is the sole cotransmitter by which MCN1 influences LG (Wood et al., 2000; Stein et al., 2007), we bath applied CabTRP Ia and CCAP to identify the ionic current(s) affected by these two pathways.

Bath-applied CCAP $\left(10^{-7} \mathrm{M}\right)$ and CabTRP Ia $\left(10^{-6} \mathrm{M}\right)$ each caused an inward shift in the holding current at a holding potential of $-60 \mathrm{mV}$ (saline: $-1.8 \pm 1.0 \mathrm{nA}$, CCAP: $-2.6 \pm 1.2 \mathrm{nA}$, $n=4, p=0.05$; saline: $-1.6 \pm 0.7 \mathrm{nA}$, CabTRP Ia: $-2.0 \pm 0.7$ $\mathrm{nA} ; n=4, p=0.003)$. Subtraction of the control total current from the total current during CCAP or CabTRP Ia application revealed a voltage-dependent inward difference current (Fig. $2 A, B)$. The peak current amplitude (CCAP: $-2.6 \pm 0.4 \mathrm{nA}, n=$ 4; CabTRP Ia: $-0.8 \pm 0.2 \mathrm{nA}, n=4$ ) occurred at $-36.3 \pm 2.4 \mathrm{mV}$ in CCAP $\left(10^{-7} \mathrm{M}: n=4\right)$ and $-36.7 \pm 6.2 \mathrm{mV}$ in CabTRP Ia $\left(10^{-6} \mathrm{M}: n=4\right)$. The half-maximal current occurred at $-51.1 \pm$ $6.3 \mathrm{mV}$ in CCAP $(n=4)$ and at $-60.9 \pm 4.2 \mathrm{mV}$ in CabTRP Ia $(n=4)$.

The voltage dependence of these peptide-elicited currents was comparable to one another and to that previously reported for $I_{\mathrm{MI}}$ in pyloric neurons (Golowasch and Marder, 1992a; Swensen and Marder, 2000). To further test whether CCAP and CabTRP Ia converged to activate the same current $\left(I_{\mathrm{MI}}\right)$ in the LG neuron, we performed occlusion experiments. Specifically, CabTRP Ia $\left(10^{-4} \mathrm{M}\right)$ was pressure applied to the desheathed STG neuropil in control conditions, then CCAP $\left(10^{-6} \mathrm{M}\right)$ was bath applied, during which the influence of CabTRP Ia $\left(10^{-4} \mathrm{M}\right)$ was again assayed. Pressure-ejected CabTRP Ia activated the aforementioned voltage-dependent inward current in the control condition (peak current: $-0.9 \pm 0.2 \mathrm{nA}, n=4$ ) (Fig. 2C). Subsequent bathapplied CCAP also activated a voltage-dependent inward current. However, pressured-ejected CabTRP Ia in the presence of CCAP elicited little to no additional current compared with 
CCAP alone (CCAP: $-1.9 \pm 0.2 \mathrm{nA}$; CCAP + CabTRP Ia: $-2.1 \pm 0.2 \mathrm{nA}, n=$ 4; CCAP vs CCAP + CabTRP Ia: $p=0.16$; CabTRP Ia alone vs CCAP + CabTRP Ia: $p<0.001$, one-way RM ANOVA followed by Student-Newman-Keuls test) (Fig. 2C). After CCAP washout, CabTRP Ia again elicited a current comparable to the pre-CCAP condition $(-1.0 \pm 0.1 \mathrm{nA}, n=$ 3; wash vs control: $p=0.91$; one-way RM ANOVA followed by Student-NewmanKeuls test). This reversible occlusion result indicated convergence of the two peptides on the same voltage-dependent inward current. Given the similar properties of this current to those of the previously identified $I_{\mathrm{MI}}$ (Golowasch and Marder, 1992a; Swensen and Marder, 2000), and the fact that CCAP and CabTRP Ia activate this current in pyloric neurons, we conclude that these peptides also activate $I_{\mathrm{MI}}$ in LG.

\section{CCAP actions in a computational}

model mimic its actions on the

biological gastric mill rhythm

We next examined the role of $I_{\mathrm{MI}-\mathrm{CCAP}}$ in LG for mediating the selective prolongation of the gastric mill protractor phase by bath-applied CCAP, using our previously developed computational model of the MCN1-gastric mill rhythm (Nadim et al., 1998; Beenhakker et al., 2005). We modeled $I_{\mathrm{MI}}$ based on values obtained in our LG voltage-clamp experiments (see above) as well as previously determined values (Golowasch and Marder, 1992a; Swensen and Marder, 2000) (Table 1). Further, we assumed that the CCAP influence was at a steady state, comparable to its continued presence during bath application of the peptide in the biological experiments (Kirby and Nusbaum, 2007), and so the $I_{\mathrm{MI}-\mathrm{CCAP}}$ amplitude and its associated $G_{\mathrm{MI}-\mathrm{CCAP}}$ were sensitive only to changes in the LG membrane potential.

The trajectory of the model $G_{\mathrm{MI}-\mathrm{MCN} 1}$ in the LG neuron steadily increased in amplitude during retraction due to continual MCN1 release of CabTRP Ia, and decayed during protraction due to feedback inhibition from $\mathrm{LG}$ onto $\mathrm{MCN1}_{\mathrm{STG}}$ (Figs. $1 C$, $3 A, B$ ) (Coleman and Nusbaum, 1994; Coleman et al., 1995; Beenhakker et al., 2005). As is evident in Figure 3, the $G_{\mathrm{MI}-\mathrm{MCN} 1}$ peak amplitude occurred at LG burst onset, from which point it decayed until it could no longer sustain the LG burst. The trajectory of the $G_{\mathrm{MI}-\mathrm{CCAP}}$ amplitude in LG during retraction was similar to that of $G_{\mathrm{MI}-\mathrm{MCN} 1}$, but was distinct during protraction where it exhibited a sustained maximal amplitude (Fig. $3 B$ ). The model $I_{\mathrm{MI}}$ trajectory in LG tracked that of $G_{\mathrm{MI}}$ for both MCN1 and CCAP, except at LG burst onset where $I_{\mathrm{MI}}$ amplitude diminished because the LG membrane potential approached $E_{\text {rev }}$ for $I_{\mathrm{MI}}$.

We used this model to test whether we could mimic the CCAP-mediated selective increase in protractor phase duration by adding $I_{\text {MI-CCAP }}$ to (1) Int1 and LG, (2) Int 1 alone, or (3) LG alone. We did not document the presence of $I_{\mathrm{MI}-\mathrm{CCAP}}$ in the bio- logical Int1, but for use in the model we assumed it to be the current responsible for the CCAP excitation of Int1. This assumption was based on the fact that it is the relevant current in all CCAP-responsive pyloric circuit neurons as well as LG (Swensen and Marder, 2000; this study).

In the model, adding $I_{\mathrm{MI}-\mathrm{CCAP}}$ to both Int 1 and LG prolonged the protractor phase relative to the control gastric mill rhythm (control: $11.0 \pm 0.4 \mathrm{~s}$; CCAP: $14.0 \pm 0.3 \mathrm{~s} ; n=3$ cycles, $p<0.05$ ) without altering the retractor phase duration (control: $7.0 \pm$ $0.2 \mathrm{~s}$; CCAP: $7.3 \pm 0.3 \mathrm{~s} ; n=3$ cycles, $p=0.39$ ). When instead $I_{\mathrm{MI}-\mathrm{CCAP}}$ was added only to Int1, there was no change in the protractor phase duration (control: $11.0 \pm 0.4$ s; CCAP: $10.4 \pm$ $0.2 \mathrm{~s} ; n=3$ cycles, $p=0.15$ ) or retractor phase duration (control: $7.0 \pm 0.2 \mathrm{~s}$; CCAP: $7.3 \pm 0.5 \mathrm{~s} ; n=3$ cycles, $p=0.21$ ). Despite the lack of effect on the gastric mill rhythm, the CCAP-activated conductance was effective at increasing the Int 1 intraburst firing frequency in the absence of a gastric mill rhythm (control: $6.9 \pm$ $0.04 \mathrm{~Hz}$; CCAP: $9.2 \pm 0.08 \mathrm{~Hz}, n=3$ cycles, $p<0.001$ ), similar to what was previously observed with biological CCAP superfusion (Kirby and Nusbaum, 2007). Last, providing $I_{\text {MI-CCAP }}$ only to LG was comparable to adding this current to both Int 1 and LG. Specifically, the gastric mill protractor phase was prolonged (control: 


\section{A Saline}

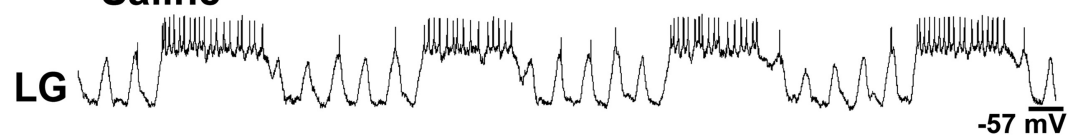

B $\operatorname{CCAP}\left(10^{-7} \mathrm{M}\right)$

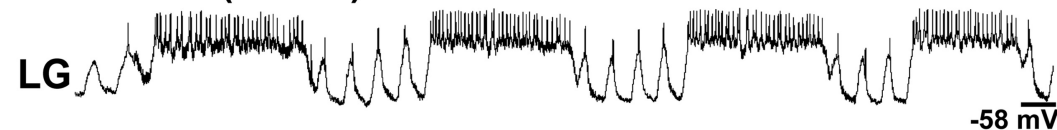

\section{C $\operatorname{CCAP}\left(10^{-7} \mathrm{M}\right)+$ Negative $\mathrm{I}_{\mathrm{MI}-\mathrm{CCAP}}$}

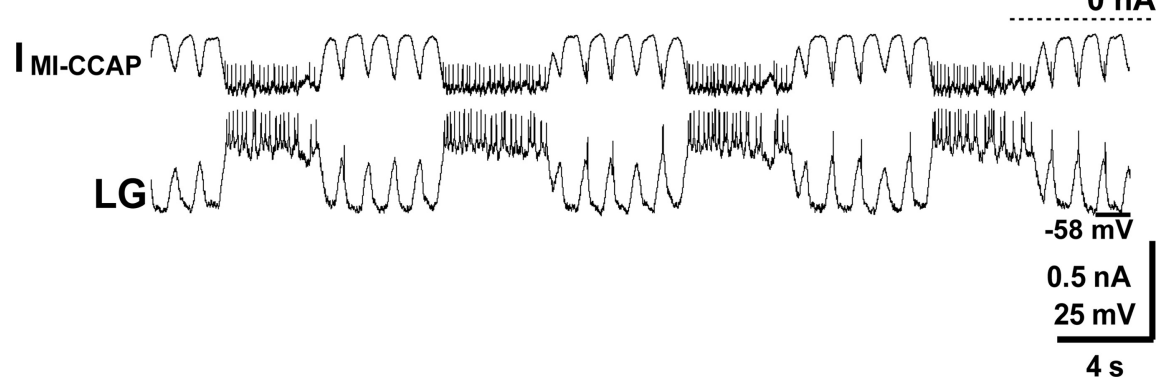

the $I_{\mathrm{MI}-\mathrm{MCN} 1}$ amplitude at LG burst offset in the CCAP condition was reduced compared with the control condition (Figs. 3, 4C).

The unchanged retractor phase duration in the versions of the model with CCAP present in either LG and Int1 or LG alone was also consistent with our previous results from the biological preparation, in which CCAP selectively prolonged the protractor phase (Kirby and Nusbaum, 2007). In these models, the $I_{\mathrm{MI}-\mathrm{MCN} 1}$ amplitude was smaller at LG burst offset with CCAP present (Figs. 3, 4). However, the continued presence of $I_{\text {MI-CCAP }}$ throughout the retractor phase apparently compensated for the reduced $I_{\mathrm{MI}-\mathrm{MCN} 1}$ amplitude, resulting in the retractor phase remaining unaltered by the presence of CCAP (Figs. 3, 4).

\section{Injecting artificial $I_{\mathrm{MI}-\mathrm{CCAP}}$ into LG selectively prolongs protractor phase activity}

We used the dynamic clamp to inject artificial $I_{\mathrm{MI}-\mathrm{CCAP}}$ selectively into the biological LG neuron and thereby test the prediction from our computational model that the CCAP action on LG is pivotal for gation of the gastric mill protractor phase. A, The MCN1-gastric mill rhythm without CCAP application. B, Bath-applied CCAP selectively prolonged the gastric mill protractor phase. $C$, Injection of a negative conductance version of MI-CCAP $_{\text {into }}$ LG during CCAP application eliminated the prolongation of the protractor phase by CCAP without altering the retractor phase duration. All three panels are from the same intracellular $L G$ recording.

$11.0 \pm 0.4 \mathrm{~s}$; CCAP: $13.8 \pm 0.3 \mathrm{~s} ; n=3$ cycles, $p<0.05)$, without altering the retractor phase duration (control: $7.0 \pm 0.2 \mathrm{~s}$; CCAP: $6.8 \pm 0.1 \mathrm{~s} ; n=3$ cycles, $p=0.27$ ) (Fig. 3 ).

In both models that exhibited an increased protractor phase duration with CCAP present, there was no change in the summed peak $I_{\mathrm{MI}}$ amplitude in LG despite the parallel activation of this current by MCN1 and CCAP. For example, in the model where $I_{\mathrm{MI}-\mathrm{CCAP}}$ was added only to LG, the summed peak $I_{\mathrm{MI}}$ amplitude was unchanged at both the start (MCN1: $-48.3 \pm 1.4 \mathrm{pA} ; \mathrm{MCN} 1$ plus CCAP: $-47.4 \pm 0.7 \mathrm{pA} ; n=3$ cycles, $p=0.35)$ and end (MCN1: $-15.2 \pm 0.5 \mathrm{pA}$; MCN1 plus CCAP: $-16.2 \pm 0.4 \mathrm{pA}$; $n=3$ cycles, $p=0.14$ ) of each LG burst (Fig. 4). Consequently, the membrane potential at which the LG burst terminated was the same whether or not $I_{\mathrm{MI}-\mathrm{CCAP}}$ was present $(\mathrm{MCN1}:-31.1 \pm$ $1.28 \mathrm{mV}$; MCN1 plus CCAP: $-29.78 \pm 1.14 \mathrm{mV}, n=4$ cycles, $p=0.15)$. Despite the fact that the total peak $I_{\mathrm{MI}}$ was unchanged, the component contributed by MCN1 $\left(I_{\mathrm{MI}-\mathrm{MCN} 1}\right)$ was decreased at LG burst onset (w/o CCAP: $-48.3 \pm 1.4 \mathrm{pA}$; w/CCAP: $-41.6 \pm 0.6 \mathrm{pA} ; n=3$ cycles, $p<0.05$ ) and offset (w/o CCAP: $-15.2 \pm 0.5 \mathrm{pA} ; \mathrm{w} / \mathrm{CCAP}:-9.4 \pm 0.3 \mathrm{pA} ; n=3$ cycles, $p<0.05)$, although the net decrease of $I_{\mathrm{MI}-\mathrm{MCN} 1}$ was essentially unchanged $(\sim 32 \mathrm{pA})$. The decreased contribution from MCN1 is shown for $G_{\mathrm{MI}}$ levels in Figure 4.

The $I_{\text {MI-CCAP }}$ amplitude was approximately constant across the duration of the LG burst and so appeared responsible for the prolonged LG burst in CCAP (Fig. 3). This $I_{\text {MI-CCAP }}$ effect resulted from its replacing a portion of the decaying $I_{\mathrm{MI}-\mathrm{MCN} 1}$ during the LG burst with a nondecaying $I_{\mathrm{MI}}$ component (Figs. 3, 4). In the CCAP condition, the total $I_{\mathrm{MI}}$ amplitude (i.e., $I_{\mathrm{MI}-\mathrm{MCN} 1}$ plus $\left.I_{\mathrm{MI}-\mathrm{CCAP}}\right)$ was equal to the $I_{\mathrm{MI}-\mathrm{MCN} 1}$ amplitude without CCAP at both LG burst onset and offset (Fig. 4). However, the presence of the nondecaying $I_{\mathrm{MI}-\mathrm{CCAP}}$ component reduced the overall decay rate of $I_{\mathrm{MI}}$, and thus prolonged the LG burst (Fig. 4C). Furthermore, because some $I_{\mathrm{MI}-\mathrm{MCN} 1}$ was replaced by $I_{\mathrm{MI}-\mathrm{CCAP}}$, its influence on the gastric mill rhythm. During the MCN1gastric mill rhythm, injecting artificial $I_{\mathrm{MI}-\mathrm{CCAP}}$ into LG over a range of conductance values $(10-30 \mathrm{nS})$ elicited a CCAP-like selective prolongation of the protractor phase. For example, using a $20 \mathrm{nS}$ conductance value, this current injection consistently increased the duration of the gastric mill cycle period (control: $9.6 \pm 1.0 \mathrm{~s} ; I_{\mathrm{MI}-\mathrm{CCAP}}: 12.2 \pm 1.4 \mathrm{~s}, n=10, p=0.003$ ) (Fig. 5). This slowing of the rhythm resulted from a selective increase in the protractor phase (LG burst) duration (control: $4.9 \pm 0.5 \mathrm{~s} ; I_{\mathrm{MI}}$ CCAP: $6.8 \pm 0.8 \mathrm{~s} ; n=10, p=0.001)$, insofar as there was no change in the retractor phase duration $(n=10, p=0.09)$ (Fig. 5). Artificial $I_{\mathrm{MI}-\mathrm{CCAP}}$ injections also selectively prolonged the protractor phase at lower $(10 \mathrm{nS}$ : protraction, $p=0.02$; retraction, $p=0.22, n=5)$ and higher ( $30 \mathrm{nS}$ : protraction, $p=0.01$; retraction, $p=0.28, n=5$ ) conductance values. When we injected $I_{\mathrm{MI}-\mathrm{CCAP}}$ into LG at $5 \mathrm{nS}$, there was no consistent change across preparations in either phase of the rhythm (protraction, $p=0.07$; retraction, $p=0.14, n=5$ ). The maximal amplitude of these CCAP-like $I_{\mathrm{MI}}$ injections (range: $0.3-1.0 \mathrm{nA}$, mean: $0.64 \pm 0.05$ $\mathrm{nA}, n=16$ ) was less than the maximal $I_{\mathrm{MI}-\mathrm{CCAP}}$ amplitude determined in voltage-clamp experiments in both pyloric neurons and the LG neuron (Golowasch and Marder, 1992a; Swensen and Marder, 2000) (this study). They were also comparable to previous dynamic-clamp $I_{\mathrm{MI}}$ injections used to study neuropeptide actions on the pyloric circuit (Swensen and Marder, 2001) and those injected into LG to drive a MCN1-like gastric mill rhythm (Beenhakker et al., 2005).

The increased LG neuron burst duration resulting from $I_{\mathrm{MI} \text {-CCAP }}$ injection presumably resulted from the associated increased depolarizing current, which was largest at the depolarized membrane potential that occurs during the LG burst (Fig. 5B). The LG burst nonetheless still terminated, despite the presence of the additional drive from $I_{\mathrm{MI} \text {-CCAP. }}$ As shown above in the computational model, LG burst termination presumably resulted 
from the fact that despite $I_{\text {MI-CCAP }}$ prolonging the LG burst, it did not prevent the continued decay of $I_{\mathrm{MI}-\mathrm{MCN} 1}$ during each LG burst to the point where LG could no longer sustain its activity (Fig. 4) (Coleman et al., 1995; Beenhakker et al., 2005).

To test whether $I_{\text {MI-CCAP }}$ alone was sufficient to elicit a LG burst, we used the dynamic clamp to inject the same simulated CCAP conductance described above into the LG neuron without MCN1 stimulation. Under this condition, injecting $I_{\text {MI-CCAP }}$ did not activate spiking in LG or change its membrane potential (control: $-61.9 \pm 2.3 \mathrm{mV} ; I_{\mathrm{MI}}:-59.0 \pm 3.6 \mathrm{mV}$; $n=3, p=0.09$ ). The lack of an evident LG response to $I_{\mathrm{MI}-\mathrm{CCAP}}$ injection presumably resulted from the relatively small amplitude of this voltage-dependent current near the resting potential (Golowasch and Marder, 1992a; Swensen and Marder, 2000; see above). Thus, $I_{\mathrm{MI}-\mathrm{CCAP}}$ alone was not sufficient to elicit a LG burst.

Injecting artificial $I_{\text {MI-CCAP }}$ into LG $\left(G_{\mathrm{MI}}: 20 \mathrm{nS}\right)$ during the gastric mill rhythm also increased the number of action potentials during the LG burst (control, $33.7 \pm 4.5$ spikes; $I_{\mathrm{MI}}: 51.2 \pm 8.5$ spikes; $n=10, p=0.002$ ) as well as its intraburst firing frequency (control: $6.6 \pm$ $\left.0.5 \mathrm{~Hz} ; \mathrm{I}_{\mathrm{MI}}: 9.6 \pm 1.7 \mathrm{~Hz} ; n=10, p<0.05\right)$ (Fig. $5 A, B$ ). These changes in LG activity were comparable to those observed during CCAP bath application (Kirby and Nusbaum, 2007).

\section{Subtracting $I_{\mathrm{MI}}$ in LG eliminates CCAP} prolongation of the protractor phase We further tested the hypothesis that the CCAP-mediated selective prolongation of the gastric mill protractor phase resulted from CCAP activation of $I_{\mathrm{MI}}$ in the LG neuron by selectively subtracting this current in LG during CCAP bath application. Specifically, during bath-applied CCAP $\left(10^{-7} \mathrm{M}\right)$, we reversed the sign of the artificial $I_{\mathrm{MI}-\mathrm{CCAP}}$ conductance (i.e., from $+20 \mathrm{nS}$ to $-20 \mathrm{nS}$ ) injected into LG while leaving all other dynamic-clamp parameters unchanged.

Injecting the negative conductance version of $I_{\text {MI-CCAP }}$ into LG during CCAP application eliminated the CCAP prolongation of the gastric mill protractor phase (control: $3.8 \pm 0.6 \mathrm{~s}$; CCAP: $5.2 \pm 0.3 \mathrm{~s}$; CCAP plus Neg. $I_{\text {MI }}: 4.3 \pm 0.3 \mathrm{~s}, n=4$; one-way ANOVA, $p<0.05$; Holm-Sidak post hoc test: CCAP vs control, $p<0.05$; all other pairwise comparisons, $p>0.05$ ) (Fig. 6). These injections had no unexpected effects on the motor pattern. For example, there was no concomitant change in the retractor phase duration (control: $5.2 \pm 1.0 \mathrm{~s}$; CCAP: $4.7 \pm 0.5 \mathrm{~s}$; CCAP plus Neg. $I_{\mathrm{MI}}: 6.6 \pm 1.3 \mathrm{~s}, n=4, p=$ significant.
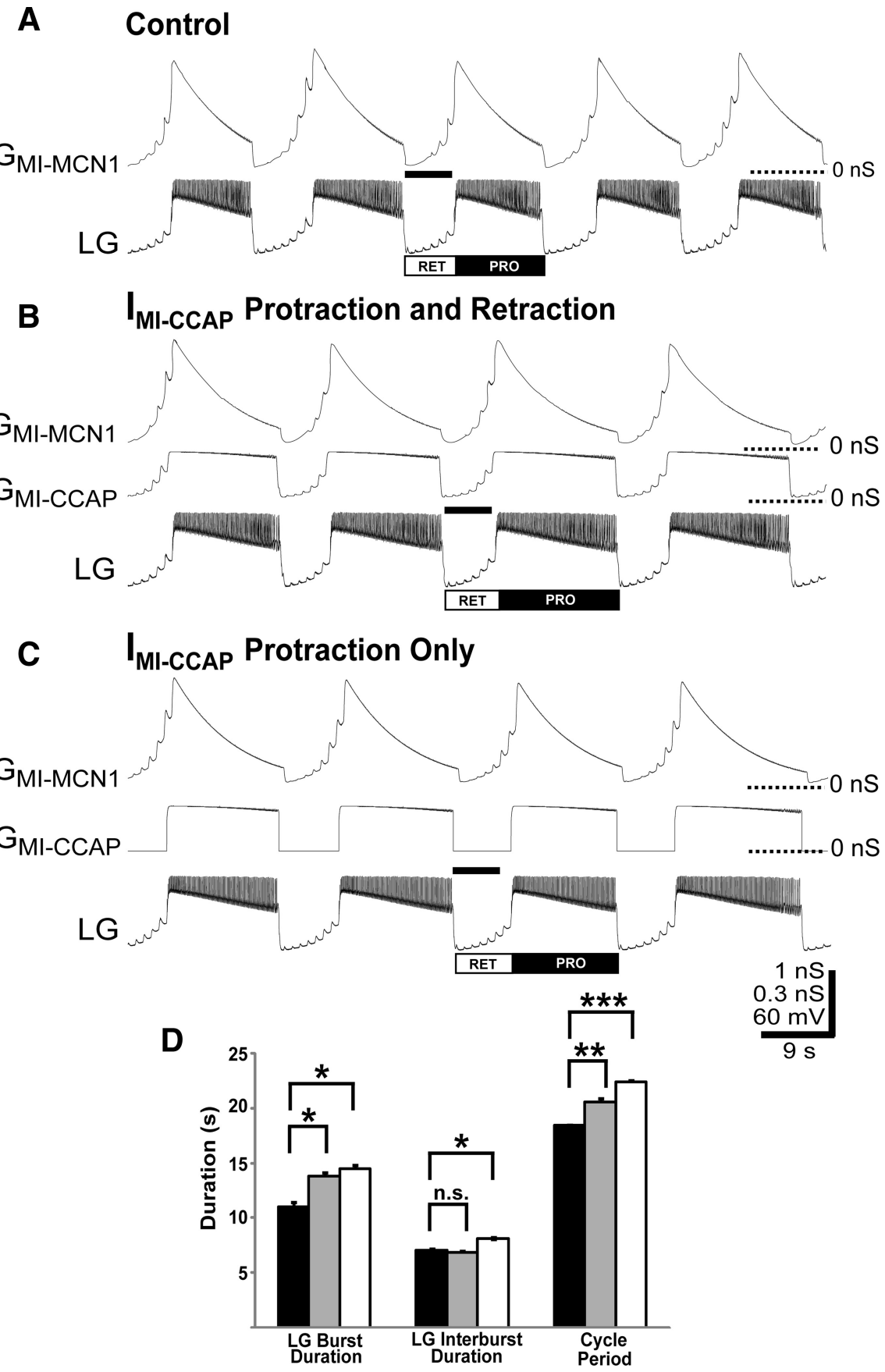

Figure 7. Limiting the influence of $I_{\mathrm{MI}-\mathrm{CCAP}}$ in $\mathrm{LG}$ to the protractor phase does not mimic the action of bath-applied CCAP on the gastric mill rhythm in a computational model. $A$, Gastric mill rhythm, driven only by MCN1 stimulation. The black bar represents the retractor phase duration. $B$, Gastric mill rhythm resulting from MCN1 stimulation during the continually present influence of CCAP. Note the prolongation of the $L G$ burst (protraction) and unchanged duration of the $L G$ interburst (retraction) relative to $A$. The black bar represents the retractor phase duration in $A$. C, Selectively providing $I_{\mathrm{MI}-\mathrm{CCAP}}$ to the gastric mill protractor phase changed the CCAP influence on the MCN1-gastric mill rhythm by prolonging retraction as well as protraction. Note that the retractor phase is prolonged relative to the black bar that represents the retractor phase duration in the control conditions. Most hyperpolarized $V_{\mathrm{m}}$

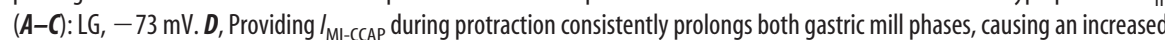
gastric mill cycle period relative to the saline and continually present $I_{\text {MI-CCAP }}$ conditions. Black bars, Saline condition; gray bars, continually present $I_{\text {MI-CCAP }}$; white bars, $I_{\text {MI-CCAP }}$ present during protraction only; ${ }^{*} p<0.05,{ }^{* *} p<0.01,{ }^{* * *} p<0.005 ;$ n.S., not

0.13). This result also confirmed the prediction of our computational model that $I_{\mathrm{MI}-\mathrm{CCAP}}$ in LG alone is sufficient to mimic the influence of bath-applied CCAP on the gastric mill rhythm. If the influence of $I_{\mathrm{MI}-\mathrm{CCAP}}$ was necessary in both LG and Int1, then selectively eliminating $I_{\mathrm{MI}-\mathrm{CCAP}}$ in LG alone 
would not have returned the gastric mill rhythm to the control condition.

$I_{\mathrm{MI}-\mathrm{CCAP}}$ in LG maintains a constant retractor phase duration It was initially surprising to learn that bath-applied CCAP did not alter the retractor phase duration (Kirby and Nusbaum, 2007). Our expectation was that, despite the fact that the $I_{\mathrm{MI}-\mathrm{CCAP}}$ amplitude in LG was likely to be relatively small during retraction, it would still summate with the MCN1-activated current. We anticipated that this summation would result in the burst threshold onset for LG occurring sooner, thereby reducing the duration of this phase. Both our model and dynamic-clamp injections did show that $I_{\mathrm{MI}-\mathrm{CCAP}}$ was indeed activated during retraction, but was smaller in amplitude than the parallel buildup of $I_{\mathrm{MI}-\mathrm{MCN} 1}$. The model, however, also suggested that the retractor phase duration was unchanged by CCAP because the $I_{\mathrm{MI}-\mathrm{CCAP}}$ compensated for the reduced level of $I_{\mathrm{MI}-\mathrm{MCN} 1}$ during retraction when CCAP was present (Fig. 4). It thus remained to be determined whether the relatively small amplitude of $I_{\mathrm{MI}-\mathrm{CCAP}}$ during retraction was nonetheless sufficient to influence the retractor phase duration.

We first used our computational model to test the hypothesis that the presence of $I_{\mathrm{MI}-\mathrm{CCAP}}$ only during protraction was sufficient to mimic the ability of bath-applied CCAP to selectively prolong protraction. To this end, we compared simulations of the MCN1-gastric mill rhythm with $I_{\text {MI-CCAP }}$ in LG being absent or continually present vs being present only during protraction (Fig. 7). In contrast to the ability of continually present $I_{\mathrm{MI}-\mathrm{CCAP}}$ to selectively prolong protraction (Fig. $7 A, B$ ), simulations where $I_{\mathrm{MI}-\mathrm{CCAP}}$ was present only during the protractor phase still prolonged protraction (control: $11.0 \pm 0.4 \mathrm{~s}$; CCAP during protraction: $14.5 \pm 0.3 \mathrm{~s} ; n=3$ cycles, $p<0.05$ ), but it also increased the retractor phase duration (control: $7.0 \pm 0.2 \mathrm{~s}$; CCAP during protraction: $8.1 \pm 0.1 \mathrm{~s} ; n=3$ cycles, $p<0.05$ ) (Fig. 7C,D).

The retractor phase was prolonged when CCAP was absent during retraction because, during the CCAP-prolonged protractor phase, $I_{\mathrm{MI}-\mathrm{MCN} 1}$ decayed to a lower level relative to rhythms without any CCAP (control: $-15.2 \pm 0.5 \mathrm{pA}$; CCAP during protraction: $-9.7 \pm 0.5 \mathrm{pA} ; n=3$ cycles, $p<0.05)$ (Fig. $7 A, C$ ). Thus, when there was no CCAP present during retraction, it took the MCN1-activated current longer to build up to the point needed to initiate the next LG burst (Fig. 7A-C). When CCAP was present continuously, the additional CCAP conductance during the retractor phase offset this effect (see above). Thus, although continuous application of the CCAP conductance to LG in our model selectively changed the protractor phase duration, its presence during retraction was also necessary for maintaining the control retractor phase duration (Fig. 7D).

We next used dynamic-clamp injections of $I_{\text {MI-CCAP }}$ to test the computational model prediction that $I_{\mathrm{MI}-\mathrm{CCAP}}$ during retraction was also necessary to enable CCAP to maintain the retraction duration unchanged from the control condition. Specifically, we injected $I_{\mathrm{MI}-\mathrm{CCAP}}\left(G_{\mathrm{MI}}: 20 \mathrm{nS}\right)$ either continuously or selectively during the protraction phase of the MCN1-gastric mill rhythm (Fig. $8 A-C$ ). The protraction-specific injections reproducibly prolonged the protractor phase (control: $7.4 \pm 1.3 \mathrm{~s}$; protractiononly $I_{\mathrm{MI}-\mathrm{CCAP}}: 12.7 \pm 2.2 \mathrm{~s} ; n=5, p=0.006$ ) (Fig. 8 ). As predicted by the model, injecting $I_{\mathrm{MI}-\mathrm{CCAP}}$ only during protraction also prolonged the retractor phase (control: $6.3 \pm 1.0 \mathrm{~s}$; protraction-only $\left.I_{\mathrm{MI}-\mathrm{CCAP}}: 8.7 \pm 1.3 \mathrm{~s} ; n=5, p=0.007\right)$. Hence, the gastric mill cycle period was increased (control: $13.7 \pm 2.0 \mathrm{~s}$; protraction-only $I_{\mathrm{MI}-\mathrm{CCAP}}: 21.3 \pm 3.2 \mathrm{~s} ; n=5, p=0.002$ ) (Fig. 8 ). Concomitant with these manipulations, there was a significant
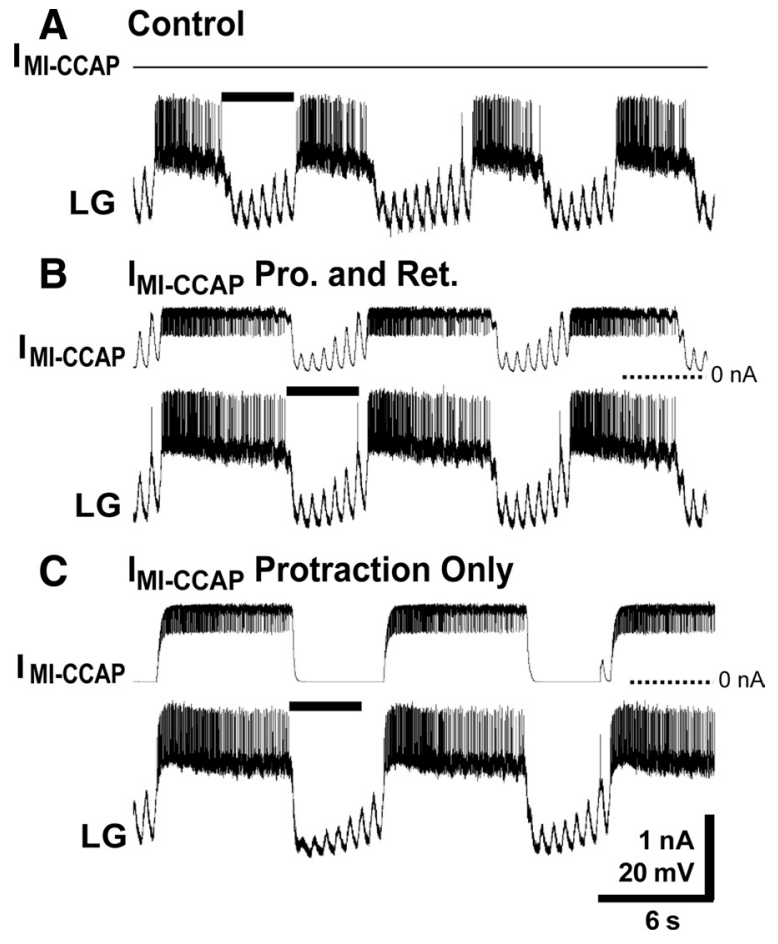

Figure 8. Limiting the influence of artificial $I_{\mathrm{MI}-\mathrm{CCAP}}$ in $\mathrm{LG}$ to the protractor phase does not mimic the action of bath-applied CCAP on the gastric mill rhythm in the biological preparation. $A$, The MCN1-gastric mill rhythm during saline superfusion. The black bar represents the retractor phase duration. $\boldsymbol{B}$, Continual injection of artificial $I_{\text {MI-CCAP }}$ into $L G$ via the dynamic clamp selectively prolonged the protractor phase. The black bar represents the retraction duration during saline superfusion. C, Protraction-only injection of artificial $I_{\text {MI-CCAP }}$ into $L G$ prolonged both phases of the gastric mill rhythm. Note prolonged retractor phase, evident by comparison to the black bar, which indicates the control duration of retraction. All panels are from the same $\mathrm{LG}$ recording. Most hyperpolarized $V_{\mathrm{m}}: \mathrm{LG},-68 \mathrm{mV}$.

increase in the number of $\mathrm{LG}$ action potentials per burst (control: $58.1 \pm 13.1$ spikes; protraction-only $I_{\text {MI-CCAP: }} 119.5 \pm 24.1$ spikes; $n=5, p=0.003$ ).

Artificial $I_{\mathrm{MI}-\mathrm{CCAP}}$ injection into LG reduces the MCN1 firing frequency threshold for gastric mill rhythm initiation CCAP superfusion also reduces the threshold MCN1 firing frequency necessary to elicit the gastric mill rhythm (Kirby and Nusbaum, 2007). The magnitude of this action ranged from $\sim 25 \%$ at higher CCAP concentrations $\left(10^{-7} \mathrm{M}\right.$ to $\left.10^{-8} \mathrm{M}\right)$ to $\sim 20 \%$ at lower CCAP concentrations $\left(10^{-9} \mathrm{M}\right.$ to $10^{-10} \mathrm{M}$ ) (Kirby and Nusbaum, 2007). This effect occurred despite the fact that $\mathrm{MCN1}_{\mathrm{STG}}$ is not CCAP-responsive (Kirby and Nusbaum, 2007). We were therefore interested to learn whether the addition of $I_{\mathrm{MI}-\mathrm{CCAP}}$ in LG was not only pivotal for altering the gastric mill motor pattern but also tuned the ability of MCN1 to activate this rhythm. Thus, we tested, first in the computational model and then in the biological preparation, whether the reduced MCN1 firing rate threshold resulted from $I_{\mathrm{MI}-\mathrm{CCAP}}$ in LG.

We first used our computational model to test whether the presence of $I_{\mathrm{MI}-\mathrm{CCAP}}$ in the LG neuron was sufficient to reduce the threshold of MCN1 stimulation needed to elicit the gastric mill rhythm. Adding $I_{\mathrm{MI}-\mathrm{CCAP}}$ to LG did reduce the MCN1 stimulation threshold by $25 \%$ (Fig. 9). Specifically, when CCAP was absent, the minimum effective MCN1 stimulation rate was $8 \mathrm{~Hz}$ for eliciting the gastric mill rhythm, while under the same conditions $6 \mathrm{~Hz}$ stimulation produced no gastric mill rhythm. How- 
ever, when $I_{\text {MI-CCAP }}$ was added to LG, $6 \mathrm{~Hz}$ MCN1 stimulation did elicit the gastric mill rhythm (Fig. 9).

In the biological preparation, when MCN1 was stimulated in the absence of the dynamic-clamp injections and at subthreshold frequency levels for activating the gastric mill rhythm, it still effectively elicited electrical coupling EPSPs (Coleman et al., 1995) and occasional action potentials in LG (Fig. $10 \mathrm{~A}$ ). In contrast, stimulating MCN1 either at a faster frequency or at the previously subthreshold frequency with $I_{\mathrm{MI}-\mathrm{CCAP}}$ injected into the LG neuron activated the gastric mill rhythm (Fig. $10 B, C$ ).

Injecting the artificial $I_{\mathrm{MI}-\mathrm{CCAP}}\left(G_{\mathrm{MI}}\right.$ : $20 \mathrm{nS}$ ) into LG consistently reduced the MCN1 threshold firing frequency for eliciting the gastric mill rhythm. As shown previously (Kirby and Nusbaum, 2007), under control conditions the minimum MCN1 firing frequency at which the gastric mill rhythm was elicited was $6.1 \pm 1.1$ $\mathrm{Hz}(n=8)$. $I_{\text {MI-CCAP }}$ injection into LG reduced this minimum frequency value by $\sim 20 \%(5.1 \pm 1.1 \mathrm{~Hz} ; n=8, p<0.001)$. To control for the possibility of timedependent changes in the effectiveness of MCN1 stimulation at near-threshold firing levels, we performed a parallel set of experiments in which we determined the threshold MCN1 firing frequency for gastric mill rhythm activation at successive time points that were equivalent to those used in the dynamic-clamp experiments. There was no change in the threshold MCN1 firing frequency value in these control experiments $(n=9, p=0.20)$.

\section{Discussion}

We have established that peptide hormone modulation of a neuronally modulated motor circuit results from the convergent hormonal and neuronal activation of the same ionic current, albeit with distinct dynamics, in a single CPG neuron. These results provide a novel mechanism by which comodulation regulates the activity of both a single neuron and its associated circuit. At the circuit level, the convergent activation of $I_{\mathrm{MI}}$ in the LG neuron enabled the peptide hormone CCAP to buoy the decaying influence of $I_{\mathrm{MI}-\mathrm{MCN} 1}$ during the LG burst and thereby prolong the protractor phase of the MCN1-elicited gastric mill rhythm. It was surprising to discover that the continual presence of $I_{\mathrm{MI}-\mathrm{CCAP}}$ was also necessary and sufficient for preventing a change in the retractor phase duration, and that the same mechanism, addition of $I_{\mathrm{MI}-\mathrm{CCAP}}$ to the LG neuron, played the distinct role of reducing the threshold firing rate at which MCN1 activates the gastric mill rhythm.

Based on our computational model, the presence of $I_{\mathrm{MI}-\mathrm{CCAP}}$ during retraction was necessary due to the reduced $I_{\mathrm{MI}-\mathrm{MCN} 1}$ amplitude at the start of retraction (i.e., LG burst offset) in the presence of CCAP, relative to the control condition (Fig. 4). Without compensation from CCAP, a reduced amount of $I_{\mathrm{MI}-\mathrm{MCN} 1}$ at the start of retraction would prolong that phase. This is because more time would be needed to build up sufficient $I_{\mathrm{MI}-\mathrm{MCN} 1}$ to enable LG to escape from Int1 inhibition and initiate its burst, as we verified by providing dynamic-clamp-injected $I_{\mathrm{MI}-\mathrm{CCAP}}$ only during protraction.

It was anticipated from previous studies that $I_{\mathrm{MI}-\mathrm{CCAP}}$ would be regulated only by voltage, whereas $I_{\mathrm{MI}-\mathrm{MCN} 1}$ would also be regulated by rhythmic feedback inhibition (Golowasch and Marder, 1992a; Swensen and Marder, 2000, 2001; Beenhakker et al., 2005). However, circuit dynamics are often nonintuitive, and it was our computational modeling results that led us to appreciate the potential role of these distinct dynamics specifically in the LG neuron for regulating the gastric mill rhythm, and for developing the testable predictions that we subsequently verified with our dynamic-clamp manipulations.

The necessity and sufficiency of the CCAP action in LG for regulating the gastric mill rhythm was not a foregone conclusion, because CCAP also excites other gastric mill neurons, including Intl (Kirby and Nusbaum, 2007). CCAP actions appear to be tuned for selectively prolonging the gastric mill protractor phase, insofar as this action occurs across at least four orders of magnitude for bath-applied CCAP $\left(10^{-10}\right.$ to $10^{-6} \mathrm{M}$ ) (Kirby and Nusbaum, 2007) and across at least a threefold range of dynamic-clamp injected CCAP-like $G_{\mathrm{MI}}(10-30 \mathrm{nS})$ (this paper).

Thus far, the motor circuit response to the simultaneous action of different neuromodulators is documented in only a few systems (Dickinson et al., 1997; Katz and Edwards, 1999; Svensson et al., 2001; McLean and Sillar, 2004; Crisp and Mesce, 2006; Koh and Weiss, 2007). However, many and perhaps all neural systems receive multiple modulatory inputs, suggesting that comodulation is a prevalent mode of network regulation (Proekt et al., 2005; Grillner, 2006; Huguenard and McCormick, 2007; Jing et al., 2007; Marder and Bucher, 2007; Doi and Ramirez, 2008; Jordan et al., 2008). 
A Control MCN1 Stimulation $(5 \mathrm{~Hz})$

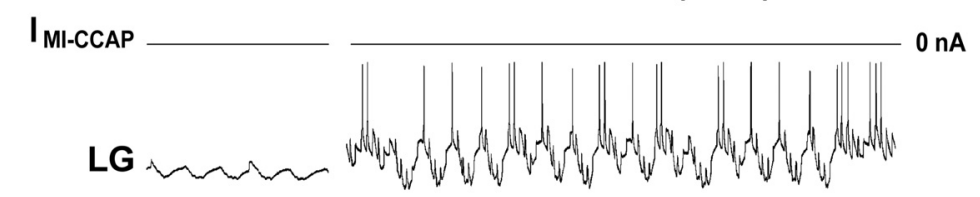

B Control MCN1 Stimulation $(6 \mathrm{~Hz})$
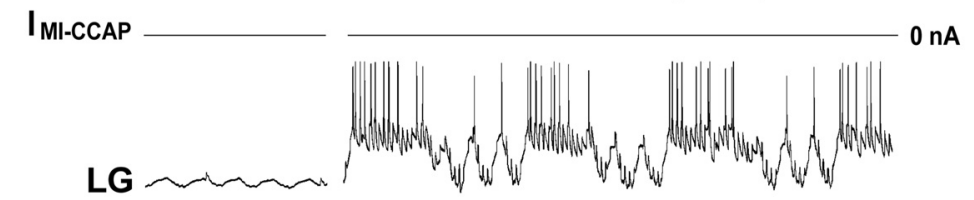

C Control MCN1 Stimulation $(5 \mathrm{~Hz})$ with $\mathrm{I}_{\mathrm{MI}-\mathrm{CCAP}}$

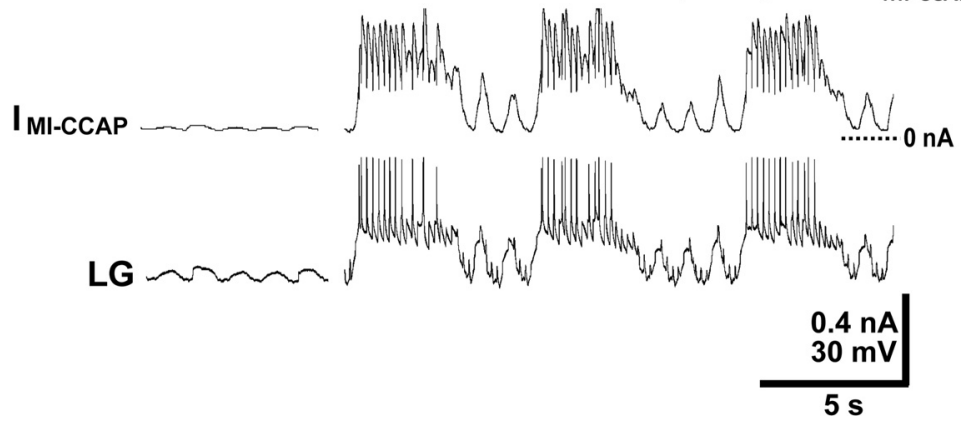

Figure 10. Injection of artificial $I_{\mathrm{MI}-C \mathrm{CAP}}$ into $\mathrm{L}$ lowers the threshold $M C N 1$ firing frequency for activating the gastric mill rhythm

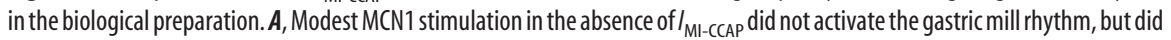
elicit unitary EPSPs and action potentials in LG. Most hyperpolarized $V_{\mathrm{m}}: \mathrm{MG},-60 \mathrm{mV}$. B, A slightly faster MCN1 stimulation frequency, without $I_{\mathrm{MI}-\text {-cCAP }}$ injection, did elicit the gastric mill rhythm. Most hyperpolarized $V_{\mathrm{m}}: \mathrm{LG},-64 \mathrm{mV}$. C, The previously subthreshold MCN1 stimulation frequency did drive the gastric mill rhythm when artificial $I_{\text {MI-ccaP }}$ was injected into LG. Most hyperpolarized $V_{\mathrm{m}}: \mathrm{LG},-64 \mathrm{mV}$.

At the single-neuron level, Swensen and Marder (2000) showed that coapplying two peptide modulators with convergent actions on the same ionic current has an additive effect on that current, similar to the convergent MCN1 and CCAP action in the LG neuron. Unlike the latter case, though, both modulators were bath applied, and hence their individual actions on the shared target current were coregulated solely by the membrane potential of the target neurons (Swensen and Marder, 2000). The convergent postsynaptic action of two inputs onto an intrinsic current via distinct dynamics also suggests a mechanistic explanation for the observation that the same modulatory substance is often present as both a circulating hormone and locally released modulator (Kristan et al., 2005; Marder and Bucher, 2007; Israel et al., 2008). Specifically, in addition to these two modes of delivery likely resulting in overlapping but distinct access to their shared receptors and their acting via different concentrations, these two delivery modes could enable a single modulator to evoke the same type of differential dynamics that we found for the convergent actions of hormonal CCAP and neuronally released CabTRP Ia.

Nontargets of a neuromodulator can play key roles in the neuronal circuit response to that modulator, while strongly affected targets sometimes play minimal roles (Hooper and Marder, 1987; Ayali and Harris-Warrick, 1999; Thirumalai et al., 2006). Similarly, two CCAP actions appeared to have little impact on the gastric mill rhythm. First, the excitation of the retractor CPG neuron Int1 by CCAP did not alter either Int 1 activity during this rhythm or the retractor phase duration in either the biological preparation (Kirby and Nusbaum, 2007) or our com- putational model (this paper). This result was supported by the ability of our dynamic-clamp subtraction of $I_{\mathrm{MI}-\mathrm{CCAP}}$ in LG during bath-applied CCAP to return the gastric mill rhythm to the control condition. Presumably the CCAP excitation of Int1 becomes effective under other conditions, such as other versions of the gastric mill rhythm (Beenhakker et al., 2004; Blitz et al., 2004; Saideman et al., 2007; Blitz et al., 2008).

Second, as discussed above, CCAP appeared to have no effect on the retraction phase, but in fact it was necessary to prevent a change in the duration of this phase (Fig. 4). Without our computational model and dynamic-clamp manipulations, we would have concluded that CCAP did not influence this phase of the rhythm. The influence of $I_{\mathrm{MI} \text {-CCAP }}$ on the retractor phase duration may well have an explicit consequence in the presence of parallel inputs to the gastric mill CPG. For example, the GPR proprioceptor neuron selectively prolongs the gastric mill retractor phase during saline superfusion (Beenhakker et al., 2005). It may be that the presence of CCAP will alter the influence of this sensory feedback system.

It was surprising that adding $I_{\mathrm{MI}-\mathrm{CCAP}}$ in LG was also sufficient to mimic the ability of bath-applied CCAP to lower the threshold MCN1 firing frequency for activating the gastric mill rhythm. In general, the ability of neuromodulation to influence a synaptic action could result from a presynaptic and/or postsynaptic site of action (LeBeau et al., 2005; Brill et al., 2007; Marder and Bucher, 2007; Doi and Ramirez, 2008; McDonald et al., 2008). For example, presynaptically, modulation can alter neuronal firing rate, action potential duration and/or the amount of transmitter released per action potential. Postsynaptically, modulation can alter the response to a synaptic action by changing intrinsic conductances and/or the responsiveness or availability of neurotransmitter receptors. Our results indicate that modulation can also alter neuronal responsiveness, and consequently circuit responsiveness, via a postsynaptic convergent activation of an ionic current. This result also further supports the hypothesis that $I_{\mathrm{MI}}$ activation exclusively in LG is pivotal for MCN1 activation of the gastric mill rhythm.

The ability of hormonal CCAP levels to lower the MCN1 firing threshold for gastric mill rhythm activation also has a potential behavioral correlate. First, even in the absence of a recent feeding episode, the steady-state level of CCAP in the hemolymph is likely to be at or above threshold for the CCAP modulation of the gastric mill rhythm (Phlippen et al., 2000; Kirby and Nusbaum, 2007). Additionally, recent work by Chen et al. (2009) suggests that several identified peptides, including CCAP, are present in the $C$. borealis hemolymph at higher levels in hungry than recently fed crabs. This observation supports the hypothesis that, in hungry crabs, what would normally be too low a MCN1 firing rate would be sufficient to initiate chewing. One source of long-term activation of MCN1 is the ventral cardiac neurons (VCNs), which are mechanosensory neurons embedded in the 
internal epithelium of the cardiac sac stomach compartment (Beenhakker et al., 2004). The cardiac sac is a food storage compartment just anterior to the gastric mill. This leads to the possibility that, in hungry crabs, modest activation of the VCNs by residual food in the cardiac sac could trigger sufficient MCN1 activity to initiate an episode of chewing. Thus, comodulation via convergence onto a single ionic conductance, as we demonstrate here, could serve as a cellular mechanism for altering a behavioral threshold.

In conclusion, the peptide hormone CCAP influences the MCN1-elicited gastric mill rhythm by its convergent activation, with MCN1-released CabTRP Ia, of a voltage-dependent inward current $\left(I_{\mathrm{MI}}\right)$ in a single CPG neuron (LG neuron). The distinct dynamics of $I_{\mathrm{MI}}$ activation and decay by these parallel inputs is pivotal to the resulting motor pattern. Paradoxically, in the presence of CCAP, the amplitude of the MCN1-activated $I_{\mathrm{MI}}$ in LG is reduced relative to saline controls (Fig. 4), yet the CCAP contribution enables the same MCN1 activity to elicit prolonged LG bursts. Last, although the gastric mill protractor phase is selectively altered by CCAP, in reality CCAP-activated $I_{\mathrm{MI}}$ is also necessary for the fact that the retractor duration is not altered. Future experiments will determine whether the presence of this peptide hormone alters the sensitivity of the gastric mill CPG to inputs that influence the apparently unchanged retractor phase.

\section{References}

Ayali A, Harris-Warrick RM (1999) Monoamine control of the pacemaker kernel and cycle frequency in the lobster pyloric network. J Neurosci 19:6712-6722.

Bartos M, Nusbaum MP (1997) Intercircuit control of motor pattern modulation by presynaptic inhibition. J Neurosci 17:2247-2256.

Bartos M, Manor Y, Nadim F, Marder E, Nusbaum MP (1999) Coordination of fast and slow rhythmic neuronal circuits. J Neurosci 19:6650-6660.

Beenhakker MP, Nusbaum MP (2004) Mechanosensory activation of a motor circuit by coactivation of two projection neurons. J Neurosci 24:6741-6750.

Beenhakker MP, Blitz DM, Nusbaum MP (2004) Long-lasting activation of rhythmic neuronal activity by a novel mechanosensory system in the crustacean stomatogastric nervous system. J Neurophysiol 91:78-91.

Beenhakker MP, DeLong ND, Saideman SR, Nadim F, Nusbaum MP (2005) Proprioceptor regulation of motor circuit activity by presynaptic inhibition of a modulatory projection neuron. J Neurosci 25:8794-8806.

Blitz DM, Christie AE, Coleman MJ, Norris BJ, Marder E, Nusbaum MP (1999) Different proctolin neurons elicit distinct motor patterns from a multifunctional neuronal network. J Neurosci 19:5449-5463.

Blitz DM, Beenhakker MP, Nusbaum MP (2004) Different sensory systems share projection neurons but elicit distinct motor patterns. J Neurosci 24:11381-11390.

Blitz DM, White RS, Saideman SR, Cook A, Christie AE, Nadim F, Nusbaum MP (2008) A newly identified extrinsic input triggers a distinct gastric mill rhythm via activation of modulatory projection neurons. J Exp Biol 211:1000-1011.

Brill J, Kwakye G, Huguenard JR (2007) NPY signaling through Y1 receptors modulates thalamic oscillations. Peptides 28:250-256.

Chen R, Ma M, Hui L, Zhang J, Li L (2009) Measurement of neuropeptides in crustacean hemolymph via MALDI mass spectrometry. J Am Soc Mass Spectrom 20:708-718.

Coleman MJ, Nusbaum MP (1994) Functional consequences of compartmentalization of synaptic input. J Neurosci 14:6544-6552.

Coleman MJ, Nusbaum MP, Cournil I, Claiborne BJ (1992) Distribution of modulatory inputs to the stomatogastric ganglion of the crab, Cancer borealis. J Comp Neurol 325:581-594.

Coleman MJ, Meyrand P, Nusbaum MP (1995) A switch between two modes of synaptic transmission mediated by presynaptic inhibition. Nature 378:502-505.

Crisp KM, Mesce KA (2006) Beyond the central pattern generator: amine modulation of decision-making neural pathways descending from the brain of the medicinal leech. J Exp Biol 209:1746-1756.
Dickinson PS, Fairfield WP, Hetling JR, Hauptman J (1997) Neurotransmitter interactions in the stomatogastric system of the spiny lobster: one peptide alters the response of a central pattern generator to a second peptide. J Neurophysiol 77:599-610.

Doi A, Ramirez JM (2008) Neuromodulation and the orchestration of the respiratory rhythm. Respir Physiol Neurobiol 164:96-104.

Goaillard JM, Marder E (2006) Dynamic clamp analyses of cardiac, endocrine, and neural function. Physiology (Bethesda) 21:197-207.

Golowasch J, Marder E (1992a) Proctolin activates an inward current whose voltage dependence is modified by extracellular $\mathrm{Ca}^{2+}$. J Neurosci 12:810-817.

Golowasch J, Marder E (1992b) Ionic currents of the lateral pyloric neuron of the stomatogastric ganglion of the crab. J Neurophysiol 67:318-331.

Grashow R, Brookings T, Marder E (2009) Reliable neuromodulation from circuits with variable underlying structure. Proc Natl Acad Sci U S A 106:11742-11746.

Grillner S (2006) Biological pattern generation: the cellular and computational logic of networks in motion. Neuron 52:751-766.

Heinzel HG, Weimann JM, Marder E (1993) The behavioral repertoire of the gastric mill in the crab, Cancer pagurus: an in situ endoscopic and electrophysiological examination. J Neurosci 13:1793-1803.

Hooper SL, Marder E (1987) Modulation of the lobster pyloric rhythm by the peptide proctolin. J Neurosci 7:2097-2112.

Huguenard JR, McCormick DA (2007) Thalamic synchrony and dynamic regulation of global forebrain oscillations. Trends Neurosci 30:350-356.

Israel JM, Poulain DA, Oliet SH (2008) Oxytocin-induced postinhibitory rebound firing facilitates bursting activity in oxytocin neurons. J Neurosci 28:385-394.

Jing J, Vilim FS, Horn CC, Alexeeva V, Hatcher NG, Sasaki K, Yashina I, Zhurov Y, Kupfermann I, Sweedler JV, Weiss KR (2007) From hunger to satiety: reconfiguration of a feeding network by Aplysia neuropeptide Y. J Neurosci 27:3490-3502.

Jordan LM, Liu J, Hedlund PB, Akay T, Pearson KG (2008) Descending command systems for the initiation of locomotion in mammals. Brain Res Rev 57:183-191.

Katz PS, Edwards DH (1999) Metamodulation: the control and modulation of neuromodulation. In: Beyond neurotransmission: neuromodulation and its importance for information processing (Katz PS, ed). New York: Oxford UP.

Khorkova O, Golowasch J (2007) Neuromodulators, not activity, control coordinated expression of ionic currents. J Neurosci 27:8709-8718.

Kirby MS, Nusbaum MP (2007) Peptide hormone modulation of a neuronally modulated motor circuit. J Neurophysiol 98:3206-3220.

Koh HY, Weiss KR (2007) Activity-dependent peptidergic modulation of the plateau-generating neuron B64 in the feeding network of Aplysia. J Neurophysiol 97:1862-1867.

Kristan WB Jr, Calabrese RL, Friesen WO (2005) Neuronal control of leech behavior. Prog Neurobiol 76:279-327.

LeBeau FE, El Manira A, Griller S (2005) Tuning the network: modulation of neuronal microcircuits in the spinal cord and hippocampus. Trends Neurosci 28:552-561.

Marder E, Bucher D (2007) Understanding circuit dynamics using the stomatogastric nervous system of lobsters and crabs. Annu Rev Physiol 69:291-316.

Marder E, Eisen JS (1984) Transmitter identification of pyloric neurons: electrically coupled neurons use different transmitters. J Neurophysiol 51:1345-1361.

McDonald NA, Kuzmiski JB, Naderi N, Schwab Y, Pittman QJ (2008) Endogenous modulators of synaptic transmission: cannabinoid regulation in the supraoptic nucleus. Prog Brain Res 170:129-136.

McLean DL, Sillar KT (2004) Metamodulation of a spinal locomotor network by nitric oxide. J Neurosci 24:9561-9571.

Nadim F, Manor Y, Nusbaum MP, Marder E (1998) Frequency regulation of a slow rhythm by a fast periodic input. J Neurosci 18:5053-5067.

Nusbaum MP, Beenhakker MP (2002) A small-systems approach to motor pattern generation. Nature 417:343-350.

Nusbaum MP, Blitz DM, Swensen AM, Wood D, Marder E (2001) The roles of co-transmission in neural network modulation. Trends Neurosci 24:146-154.

Phlippen MK, Webster SG, Chung JS, Dircksen H (2000) Ecdysis of decapod crustaceans is associated with a dramatic release of crustacean cardioactive peptide into the haemolymph. J Exp Biol 203:521-536. 
Prinz AA, Abbott LF, Marder E (2004) The dynamic clamp comes of age. Trends Neurosci 27:218-224.

Proekt A, Vilim FS, Alexeeva V, Brezina V, Friedman A, Jing J, Li L, Zhurov Y, Sweedler JV, Weiss KR (2005) Identification of a new neuropeptide precursor reveals a novel source of extrinsic modulation in the feeding system of Aplysia. J Neurosci 25:9637-9648.

Saideman SR, Blitz DM, Nusbaum MP (2007) Convergent motor patterns from divergent circuits. J Neurosci 27:6664-6674.

Sharp AA, O'Neil MB, Abbott LF, Marder E (1993) The dynamic clamp: artificial conductances in biological neurons. Trends Neurosci 16:389-394.

Stein W, DeLong ND, Wood DE, Nusbaum MP (2007) Divergent cotransmitter actions underlie motor pattern activation by a modulatory projection neuron. Eur J Neurosci 26:1148-1165.

Svensson E, Grillner S, Parker D (2001) Gating and braking of short- and long-term modulatory effects by interactions between colocalized neuromodulators. J Neurosci 21:5984-5992.
Swensen AM, Marder E (2000) Multiple peptides converge to activate the same voltage-dependent current in a central pattern-generating circuit. J Neurosci 20:6752-6759.

Swensen AM, Marder E (2001) Modulators with convergent cellular actions elicit distinct circuit outputs. J Neurosci 21:4050-4058.

Thirumalai V, Prinz AA, Johnson CD, Marder E (2006) Red pigment concentrating hormone strongly enhances the strength of feedback to the pyloric rhythm oscillator but has little effect on pyloric rhythm period. J Neurophysiol 95:1762-1770.

Weimann JM, Meyrand P, Marder E (1991) Neurons that form multiple pattern generators: identification and multiple activity patterns of gastric/ pyloric neurons in the crab stomatogastric system. J Neurophysiol 65:111-122.

Wood DE, Stein W, Nusbaum MP (2000) Projection neurons with shared cotransmitters elicit different motor patterns from the same neural circuit. J Neurosci 20:8943-8953. 